\title{
EFFECT OF THE TURBULENCE MODEL ON THE HEAT VENTILATION ANALYSIS IN A BOX PROTOTYPE
}

\author{
Hani BENGUESMIA ${ }^{1,2, *}$, Badis BAKRI ${ }^{3}$, Zied DRISS ${ }^{4}$, Ahmed KETATA ${ }^{4}$, Slah DRISS ${ }^{4}$ \\ ${ }^{1}$ Electrical Engineering Laboratory(LGE), University of M'sila, M'sila, Algeria. \\ ${ }^{2}$ Department of Electrical Engineering, Faculty of Technology, University of M'sila, M'sila, Algeria. \\ ${ }^{3}$ Department of Mechanical Engineering, Faculty of Technology, University of M'sila, M'sila Algeria. \\ ${ }^{4}$ Laboratory of Electro-Mechanic Systems (LASEM), National School of Engineers of Sfax (ENIS), University \\ of Sfax, Sfax, Tunisia \\ E-mail ${ }^{*}$ hanibenguesmia16@gmail.com \& hani.benguesmia@univ-msila.dz
}

\begin{abstract}
Investigations of the flow in a building system are crucial for understanding the fundamental basis of the aerodynamic structure characteristics. The CFD simulations were conducted using ANSYS Fluent 17.0 software, which solves the Navier-Stokes equations in conjunction with different turbulence models and by a finite volume discretization method. Particularly, a comparison between the experimental and standard k- $\omega$, BSL k- $\omega$, SST k- $\omega$, standard k- $\varepsilon$, RNG k- $\varepsilon$ and Realizable k- $\varepsilon$ turbulence model has been developed. The comparison between the founded results affirms that the standard $\mathrm{k}-\omega$ turbulence model is the most efficient to model the air flow in the present application. Indeed, the numerical results compared using the experimental data developed in the LASEM laboratory confirms the validity of the numerical method. The good agreements validate the considered computational method.
\end{abstract}

Keywords: CFD, turbulence models, heat ventilation, box prototype, solar system.

\section{INTRODUCTION}

Heat ventilation of buildings by solar energy is used for wide range applications, such as hospitals, residential and commercial buildings.

One of the chief benefits the solar ventilation is the reduction of the energy consumption by using renewable sources (renewable energy) [1-6].

The mechanism of Heat ventilation has been investigated by many researchers.

In particular, Driss et al. [4] investigated thermal comfort evaluation and the heat ventilation in a living room. In others applications, Teodosiu et al. [7] presented experimental-numerical comparisons to give the precision of a CFD model. $\mathrm{Du}$ et al. [8] conducted experimental results measurements to present the characteristics of a Chinese house. Homod et al. [9] studied and proposed a new system by coupling reasons of internal conditions that are influenced by the outdoor environment. Terrados and Moreno [10] integrated the architectural concepts with energy efficient. Yasa [11] analysed the inside regions and the surrounding areas of education buildings and performed the microclimatic comfort. Premrov et al. [12] studied a single storey house wood frame case for objective to avoid the last energy. Johnston [13] predicted and measured performance of the building fabric in new build dwellings. Chan et al. [14] modeled a building of 21 floors by using Energy plus.
The results of simulations indicate that the apartments flat present satisfactory periods for the environment. Ibrahim et al. [15] planned technical coating projection. The proposed mathematical model was compared with experimental results. Nam and Chae [16] developed an optimal design of the grounding by using a numerical method. Alam et al. [17] improves a method of releasing heat from the building to reduce the energy demand of the building in a tropical environment. Rode [18] illustrated global relations to highlight the building performance. Han et al. [19] investigated hybrid solar energy system.

A general view of the architectural envelope designs and innovative system was presented. Watson [20] reviewed design quality research on buildings in relation to users. Sailor et al. [21] describe the system use implications that lead to building energy of green roof design decisions. From these different anterior works, it has been noted that the design of buildings based on the reduction of the energy consumed. For thus, we have involved the study of the heat ventilation in a box prototype (living room).

Particularly, we have considered the turbulence models effect to choose the most effective model.

The numerical results obtained in this work were validated via a living room realized in the LASEM laboratory. 


\section{BOX PROTOTYPE SYSTEM}

Figure 1 depicts the physical domain of the box prototype (living room). The gravity direction in the system is gives as $\vec{g}=-g \vec{y}$.The box is characterized by a $0.22 \mathrm{~m}$ of height, $0.2 \mathrm{~m}$ of width and $0.3 \mathrm{~m}$ of length. Both square holes are localized at the same wall of the box.

It has the same edge which equal to $0.02 \mathrm{~m}$, while it has different distance from the bottom wall of the box. The down hole is situated with a distance equal to $\mathrm{h}_{1}=0.05 \mathrm{~m}$ from the bottom wall, which used to receive the air flow coming from the outside of the box prototype. However, the top hole is responsible to the evacuation of the air flow from the box to the surrounding air [1]. It is situated from the box base with a distance equal to $h_{2}=0.18 \mathrm{~m}$.

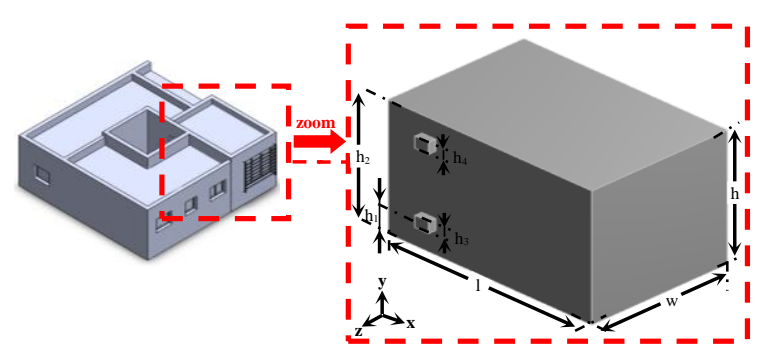

Fig. 1. 3D view of the prototype.

\section{NUMERICAL PARAMETERS}

\subsection{Boundary conditions}

The applied boundary conditions of the considered system are shown in figure 2 .

In the first hole, the heat flow supplies the box prototype from the outside air heater, where the velocity inlet and the temperature are equal respectively to $\mathrm{V}=3.4 \mathrm{~m} . \mathrm{s}^{-1}$ and $\mathrm{T}=310 \mathrm{~K}$. After that, the air flow is evacuated from the second hole of the box prototypes, where the outlet pressure is equal to $\mathrm{p}=101325 \mathrm{~Pa}$.

The others side surfaces of the box prototype are assumed as walls surrounding the computational domain.

In these surfaces, Dirichlet boundary conditions are imposed and admit these values $\mathrm{V}=0 \mathrm{~m} . \mathrm{s}^{-1}$ and $\mathrm{T}=290 \mathrm{~K}$.

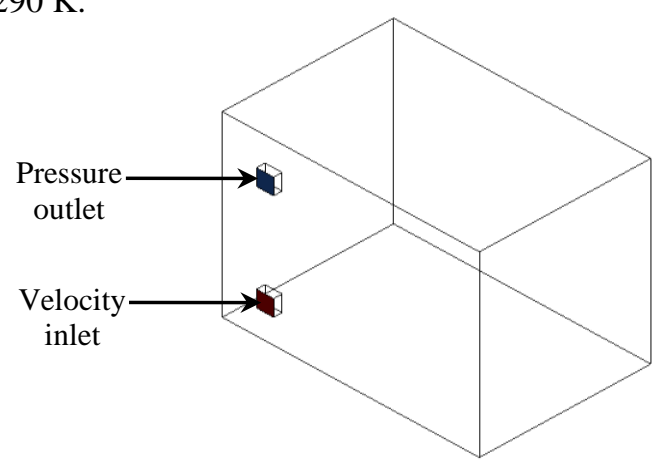

Fig. 2. Boundary conditions.

\subsection{Meshing}

The meshing is an amportant step in the simulation procudure which affect directly the accuracy of the computantional findings. Then a meshing analysis is required to minimize the error calculation.

In the present study, the employed mesh density is taken from an aterior meshing analysis [22] which is compared different meshing cases with our experimental data.

The meshing choice is based on both accuracy and calculation time [23]. Figure 3 shows a view of the used optimal mesh with a tetrahedral volume cells. The 3D computantional domain is caractirezed by 167400 cells and 64312 nodes.

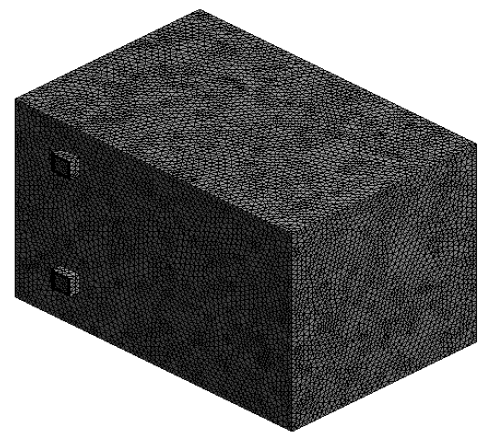

Fig. 3. Meshing.

\subsection{Numerical model}

The considered governing equations are the momentum equations, the energy equation and finally the continuity equation [24-26].

Taking a time average yields in the instantaneous equations, the Reynolds-averaged Navier-Stokes (RANS) equations can be written as follows:

$$
\begin{aligned}
& \frac{\partial \rho}{\partial t}+\frac{\partial}{\partial x_{i}}\left(\rho u_{i}\right)=0 \\
& \frac{\partial}{\partial t}\left(\rho u_{i}\right)+\frac{\partial}{\partial x_{j}}\left(\rho u_{i} u_{j}\right)=-\frac{\partial p}{\partial x_{j}}\left[\mu\left(\frac{\partial u_{i}}{\partial x_{j}}+\frac{\partial j_{i}}{\partial x_{i}}-\frac{2}{3}\right)\right] \\
& +\frac{\partial}{\partial x_{j}}\left(-\rho \overline{u_{i}^{\prime} u_{j}^{\prime}}\right) F_{i}
\end{aligned}
$$

To close equation (2), these Reynolds stresses $-\rho \overline{u_{i}^{\prime} u_{j}^{\prime}}$ must be modeled by using the Boussinesq hypothesis, written as follows:

$$
-\rho \overline{u_{i}^{\prime} u_{j}^{\prime}}=\mu_{t}\left(\frac{\partial u_{i}}{\partial x_{j}}+\frac{\partial u_{j}}{\partial x_{i}}\right)-\frac{2}{3}\left(\rho k+\mu_{t} \frac{\partial u_{k}}{\partial x_{k}}\right) \delta_{i j}
$$

The energy equation is expressed as follows:

$$
\begin{aligned}
& \frac{\partial}{\partial t}(\rho E)+\frac{\partial}{\partial x_{i}}\left[u_{i}(\rho E+p)\right]= \\
& \frac{\partial}{\partial x_{j}}\left[\left(k+\frac{c_{p} \mu_{t}}{\operatorname{Pr}_{t}}\right) \frac{\partial T}{\partial x_{j}}+u_{i}\left(\tau_{i j}\right)_{e f f}\right]+S_{h}
\end{aligned}
$$

Where $k$ is the thermal conductivity and $E$ is the total energy. 
$\left(\tau_{i j}\right)_{e f f}$ is the deviatoric stress tensor and is written as follows:

$$
\left(\tau_{i j}\right)_{e f f}=\mu_{e f f}\left(\frac{\partial u_{j}}{\partial x_{i}}+\frac{\partial u_{i}}{\partial x_{j}}\right)-\frac{2}{3} \mu_{e f f} \frac{\partial u_{k}}{\partial x_{k}} \delta_{i j}
$$

The standard model $k-\varepsilon$ is modeling by both transport equations of the turbulent kinetic energy $k$ and its dissipation rate $\varepsilon$. These equations are obtained from the following expressions:

$$
\begin{aligned}
& \frac{\partial}{\partial t}(\rho k)+\frac{\partial}{\partial x_{j}}\left(\rho k u_{i}\right)=\frac{\partial}{\partial x_{j}}\left[\left(\mu+\frac{\mu_{t}}{\sigma_{k}}\right) \frac{\partial k}{\partial x_{j}}\right] \\
& +G_{k}+G_{b}-\rho \varepsilon-Y_{M}+S_{k} \\
& \frac{\partial}{\partial t}(\rho \varepsilon)+\frac{\partial}{\partial x_{i}}\left(\rho \varepsilon u_{i}\right)=\frac{\partial}{\partial x_{j}}\left[\left(\mu+\frac{\mu_{t}}{\sigma_{\varepsilon}}\right) \frac{\partial \varepsilon}{\partial x_{j}}\right] \\
& +C_{1 \varepsilon} \frac{\varepsilon}{k}\left(G_{k}+C_{3 \varepsilon} G_{b}\right)-C_{2 \varepsilon} \frac{\varepsilon^{2}}{k}+S_{\varepsilon}
\end{aligned}
$$

$\mu_{t}$ is the turbulent viscosity computed from the combination of $k$ and $\varepsilon$ :

$$
\mu_{t}=\rho C_{\mu} \frac{k^{2}}{\varepsilon}
$$

Table 1.a illustrates the different constants employed in the $k$ - $\varepsilon$ model.

The $R N G k-\varepsilon$ model presents similarity with the standard $k-\varepsilon$ model:

$$
\frac{\partial}{\partial t}(\rho k)+\frac{\partial}{\partial x_{i}}\left(\rho k u_{i}\right)=\frac{\partial}{\partial x_{j}}\left(\alpha_{k} \mu_{e f f} \frac{\partial k}{\partial x_{j}}\right)
$$$$
+G_{k}+G_{b}-\rho \varepsilon-Y_{M}+S_{k}
$$

$$
\begin{aligned}
& \frac{\partial}{\partial t}(\rho \varepsilon)+\frac{\partial}{\partial x_{i}}\left(\rho \varepsilon u_{i}\right)=\frac{\partial}{\partial x_{j}}\left(\alpha_{\varepsilon} \mu_{e f f} \frac{\partial \varepsilon}{\partial x_{j}}\right) \\
& +C_{1 \varepsilon} \frac{\varepsilon}{k}\left(G_{k}+C_{3 \varepsilon} G_{b}\right)-C_{2 \varepsilon} \rho \frac{\varepsilon^{2}}{k}-R_{\varepsilon}+S_{\varepsilon}
\end{aligned}
$$

In these conditions, we have to write:

$$
\begin{aligned}
& d\left(\frac{\rho^{2} k}{\sqrt{\varepsilon \mu}}\right)=1.72 \frac{\hat{v}}{\sqrt{\hat{v}^{3}-1+C_{v}}} d \hat{v} \\
& \hat{v}=\frac{\mu_{\text {eff }}}{\mu} \\
& C_{v} \approx 100
\end{aligned}
$$

The difference between the $R N G$ and the standard $k-\varepsilon$ models consists in the addition of this term:
$R_{\varepsilon}=\frac{C_{\mu} \rho \eta^{3}\left(1-\eta / \eta_{0}\right)}{1+\beta \eta^{3}} \frac{\varepsilon^{3}}{k}$

Where:

$\eta=S \frac{k}{\varepsilon}$

$S=\sqrt{2 S_{i j} S_{i j}}$

Table 1.b. illustrates the different constants employed in the $R N G k-\varepsilon$ model.

In the realizable $k-\varepsilon$ model, the transport equation is giving as follows:

$$
\begin{aligned}
& \frac{\partial}{\partial t}(\rho k)+\frac{\partial}{\partial x_{j}}\left(\rho k u_{j}\right)=\frac{\partial}{\partial x_{j}}\left[\left(\mu+\frac{\mu_{t}}{\sigma_{k}}\right) \frac{\partial k}{\partial x_{j}}\right] \\
& +G_{k}+G_{b}-\rho \varepsilon-Y_{M}+S_{k} \\
& \frac{\partial}{\partial t}(\rho \varepsilon)+\frac{\partial}{\partial x_{j}}\left(\rho \varepsilon u_{j}\right)=\frac{\partial}{\partial x_{j}}\left[\left(\mu+\frac{\mu_{t}}{\sigma_{\varepsilon}}\right) \frac{\partial \varepsilon}{\partial x_{j}}\right] \\
& +\rho C_{1} S \varepsilon-\rho C_{2} \frac{\varepsilon^{2}}{k+\sqrt{v \varepsilon}}+C_{1 \varepsilon} \frac{\varepsilon}{k} C_{3 \varepsilon} G_{b}+S_{\varepsilon}
\end{aligned}
$$

Where:

$$
C_{1}=\max \left[0.43 \frac{\eta}{\eta+5}\right]
$$

As other $k-\varepsilon$ models, the turbulent viscosity is calculated as follows:

$$
\mu_{t}=\rho C_{\mu} \frac{k^{2}}{\varepsilon}
$$

The difference between the realizable $\mathrm{k}-\varepsilon$, the standard $\mathrm{k}-\varepsilon$ and the RNG $\mathrm{k}-\varepsilon$ models consists on the calculation of $C_{\mu}$, as $C_{\mu}$ is:

$$
C_{\mu}=\frac{1}{A_{0}+A_{s} \frac{k U^{*}}{\varepsilon}}
$$

Table 1.c illustrates the different constants employed in the realizable $k-\varepsilon$ model.

In the $k-\omega$ standard model, the transport equations of the specific dissipation rate $\omega$ and the turbulent kinetic energy $k$ and are written as follows:

$$
\begin{aligned}
& \frac{\partial}{\partial t}(\rho k)+\frac{\partial}{\partial x_{i}}\left(\rho k u_{i}\right)=\frac{\partial}{\partial x_{j}}\left(\Gamma_{\omega} \frac{\partial k}{\partial x_{j}}\right)+G_{k}+Y_{k}(21) \\
& +S_{k} \\
& \frac{\partial}{\partial t}(\rho \omega)+\frac{\partial}{\partial x_{i}}\left(\rho \omega u_{i}\right)=\frac{\partial}{\partial x_{j}}\left(\Gamma_{\omega} \frac{\partial k}{\partial x_{j}}\right)+G_{\sigma}+Y_{\omega} \\
& +S_{\omega}
\end{aligned}
$$


Table 1.d. illustrates the different constants employed in the $k-\omega$ model.

The BSL (Baseline) $k-\omega$ model presents a similar form:

$$
\begin{aligned}
& \frac{\partial}{\partial t}(\rho k)+\frac{\partial}{\partial x_{i}}\left(\rho k u_{i}\right)=\frac{\partial}{\partial x_{j}}\left(\Gamma_{k} \frac{\partial k}{\partial x_{j}}\right)+G_{k}+Y_{k} \\
& +S_{k}
\end{aligned}
$$

$$
\frac{\partial}{\partial t}(\rho \omega)+\frac{\partial}{\partial x_{i}}\left(\rho \omega u_{i}\right)=\frac{\partial}{\partial x_{j}}\left(\Gamma_{k} \frac{\partial \omega}{\partial x_{j}}\right)+G_{\omega}+Y_{\omega}
$$

$+D_{\omega}+S_{\omega}$

Constants of the BSL $k-\omega$ model are presented in table 1.e.

Table 1.e. illustrates the different constants of the BSL $k$ - $\omega$ model.

To make the SST $k$ - $\omega$ model more accurate, it included all the refinements of the BSL $k$ - $\omega$ model. Constants of the SST $k-\omega$ model are presented in table 1.f.

Table 1. Constants of the turbulence models

\begin{tabular}{|c|c|c|c|c|}
\hline $\mathbf{C}_{1 \varepsilon}$ & $\mathbf{C}_{2 \varepsilon}$ & $\mathbf{C}_{\mathbf{u}}$ & $\boldsymbol{\sigma}_{\mathbf{k}}$ & $\boldsymbol{\sigma}_{\boldsymbol{\varepsilon}}$ \\
\hline 1.44 & 1.92 & 0.09 & 1.0 & 1.3 \\
\hline
\end{tabular}

(a) Standard k- $\varepsilon$ model

\begin{tabular}{|c|c|c|c|}
\hline $\mathbf{C}_{\mathbf{1}}$ & $\mathbf{C}_{\mathbf{2} \varepsilon}$ & $\boldsymbol{\beta}$ & $\boldsymbol{\eta}_{\mathbf{0}}$ \\
\hline 1.44 & 1.92 & 0.012 & 4.38 \\
\hline
\end{tabular}

(b) RNG k- $\varepsilon$ model

\begin{tabular}{|c|c|c|c|}
\hline $\mathbf{C}_{\mathbf{1}}$ & $\mathbf{C}_{\mathbf{2} \varepsilon}$ & $\boldsymbol{\sigma}_{\mathbf{k}}$ & $\boldsymbol{\sigma}_{\boldsymbol{\varepsilon}}$ \\
\hline 1.44 & 1.9 & 1.0 & 1.2 \\
\hline
\end{tabular}

(c) Realizable k- $\varepsilon$ model

\begin{tabular}{|c|c|c|c|c|c|c|}
\hline $\boldsymbol{\alpha}_{0}$ & $\boldsymbol{\alpha}_{\infty}$ & $\boldsymbol{\alpha}_{\infty}^{*}$ & $\mathbf{R}_{\boldsymbol{\omega}}$ & $\mathbf{R}_{\mathbf{k}}$ & $\boldsymbol{\sigma}_{\mathbf{k}}$ & $\boldsymbol{\alpha}_{\boldsymbol{\omega}}$ \\
\hline 1.9 & 1.9 & 1.0 & 2.95 & 6.0 & 2.0 & 2.0 \\
\hline
\end{tabular}

(d) Standard k- $\omega$ model

\begin{tabular}{|c|c|c|c|c|c|}
\hline $\boldsymbol{\sigma}_{\mathbf{k}, \mathbf{1}}$ & $\boldsymbol{\sigma}_{\mathbf{k}, \mathbf{2}}$ & $\boldsymbol{\sigma}_{\boldsymbol{\omega}, \mathbf{1}}$ & $\boldsymbol{\sigma}_{\boldsymbol{\omega}, \mathbf{2}}$ & $\boldsymbol{\beta}_{\mathbf{i}, \mathbf{1}}$ & $\boldsymbol{\beta}_{\mathbf{i}, \mathbf{2}}$ \\
\hline 2.0 & 1.0 & 2.0 & 1.168 & 0.075 & 0.0828 \\
\hline
\end{tabular}

(e) BSL k- $\omega$ model

\begin{tabular}{|c|c|c|c|c|c|c|}
\hline $\boldsymbol{\sigma}_{\mathrm{k}, \mathbf{1}}$ & $\boldsymbol{\sigma}_{\mathrm{k}, \mathbf{2}}$ & $\boldsymbol{\sigma}_{\boldsymbol{\omega}, \mathbf{1}}$ & $\boldsymbol{\sigma}_{\boldsymbol{\omega}, \mathbf{2}}$ & $\boldsymbol{\beta}_{\mathbf{i}, \mathbf{1}}$ & $\boldsymbol{\beta}_{\mathbf{i}, \mathbf{2}}$ & $\mathbf{a}_{\mathbf{1}}$ \\
\hline 1.176 & 1.0 & 2.0 & 1.168 & 0.075 & 0.0828 & 0.31 \\
\hline
\end{tabular}

(f) SST k- $\omega$ model

\section{CHOICE OF THE TURBULENCE MODEL}

The effect of the turbulence model on the numerical results have been studied in this section in order to achieve the adequate model.
In fact, different turbulence models were studied using the software " Ansys Fluent 17.0" for solving the governing equations.

Particularly, we have compared the BSL $k$ - $\omega$ turbulence model, the standard $k-\omega$ turbulence model, the standard $k-\varepsilon$ turbulence model, the SST $k$ - $\omega$ turbulence model, the Realizable k- $\varepsilon$ turbulence model and the $R N G k-\varepsilon$ turbulence model.

We found that the numerical results are in good agreement with the experimental data (the velocity profile) which confirms the validity of the numerical method.

In the viewed direction, in the viewed direction, set by the intersection of the two planes $x=0.06 \mathrm{~m}$ and $z=-0.005 \mathrm{~m}$, the superposition of the experimental results with the velocity profiles for the different turbulence models is presented in figure 4.

According to these results, that the same profiles of the velocity have been observed and the values take down of the turbulence model. Particularly, it has been observed that the value founded with the experimental data is nearest to the standard $k-\omega$ tubulence model results.

This study tends to show that the standard $k-\omega$ turbulence model is the most efficient to model the air flow in the present application. Therefore, the overall error designed between the numerical and the experimental data is equal to $5 \%$.

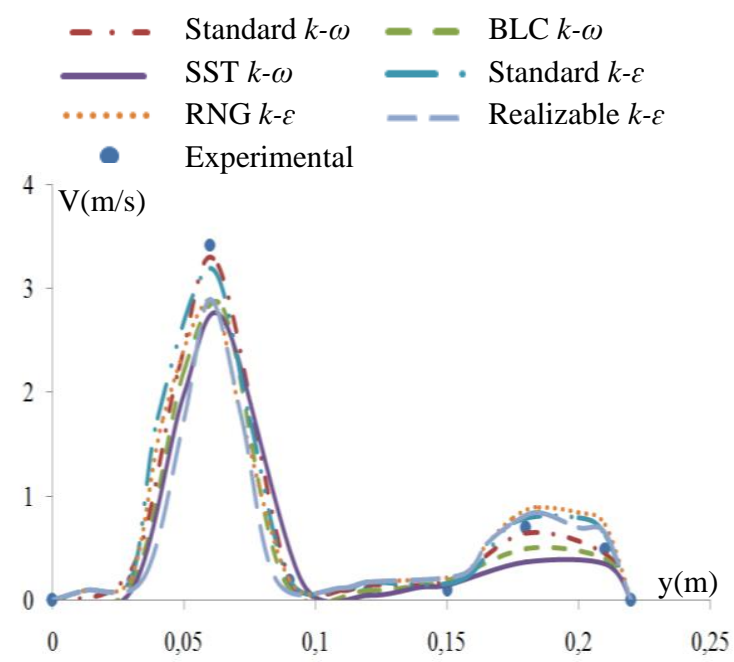

Fig. 4. Velocity profiles in the direction defined by $\mathrm{z}=-0.005 \mathrm{~m}$ and $\mathrm{x}=0.06 \mathrm{~m}$.

\section{RESULTS AND DISCUSSION}

The distribution of the velocity fields, the temperature, the total pressure, the turbulent kinetic energy and the turbulent viscosity are studied in this section.

In the present study, the employed Reynolds number is equal to $\operatorname{Re}=5100$.

\subsection{Velocity fields}

The distribution of the velocity fields in the plane defined by $\mathrm{x}=0.06 \mathrm{~m}$ is shown in figure 5 for the different studied turbulence models. From these 
results, it has been observed a discharge zone at the box inlet hole in all cases with average velocity equal to $\mathrm{V}=3.4 \mathrm{~m} \cdot \mathrm{s}^{-1}$. The inlet flow barge into the reverse wall of the box and then it moves inside the box with a turbulent behavior to evacuate through the top hole. Otherwise, both axial directions of the airflow are seen inside the box. The recirculation zone appeared in the whole area of the box is created by the change of the flow direction, specially by the first ascending flow. Meanwhile, the weak zone showed in the down area of the box is created by the second descending flow.
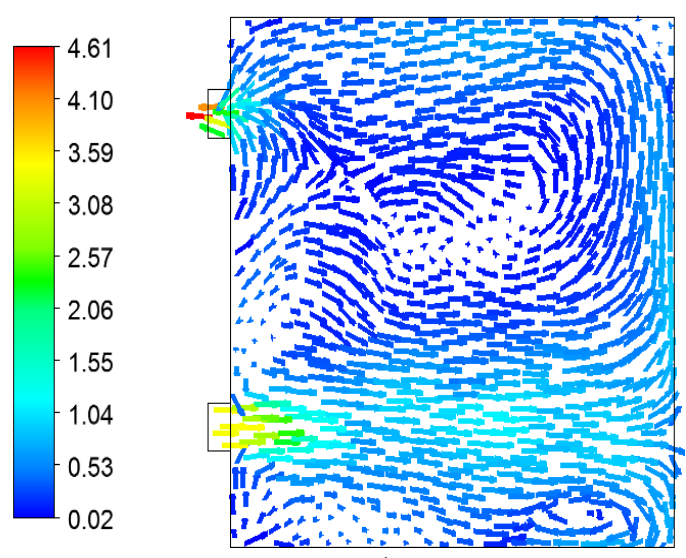

(a) Standard k- $\omega$
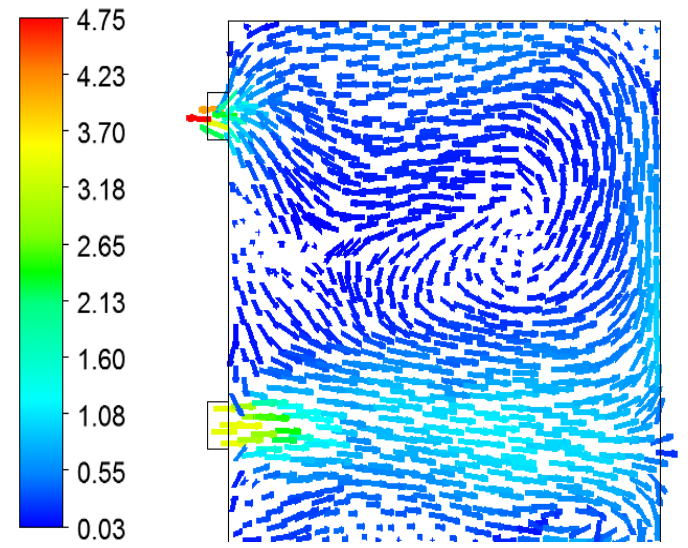

(c) SST k- $\omega$
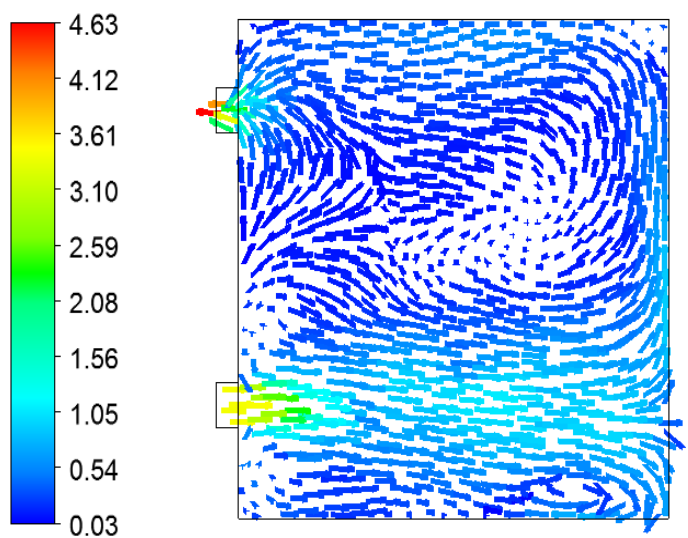

(e) RNG k-
In these conditions, the averaged velocity presents a very low value in the whole system when exclude the values in the discharge area which reached $\mathrm{V}=1.3 \mathrm{~m} \cdot \mathrm{s}^{-1}$. The comparison between the different turbulence models affirms that the choice of the adequate model presents a straight effect on the velocity fields. Particularly, it is noticed that the recirculation zone has been involved by the turbulence model choice. In this situation, the maximum value of the averaged velocity is obtained for the SST k- $\omega$ turbulence model and it reachs $V=4.75 \mathrm{~m} . \mathrm{s}^{-1}$. However, the minimum value is founded for the standard $\mathrm{k}-\varepsilon$ turbulence model and it reachs $\mathrm{V}=4.42 \mathrm{~m} . \mathrm{s}^{-1}$.
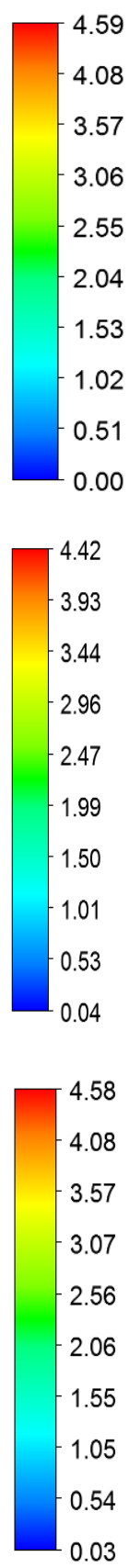

.04

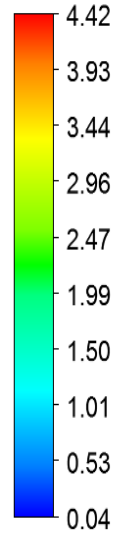

\begin{abstract}
.03
\end{abstract}

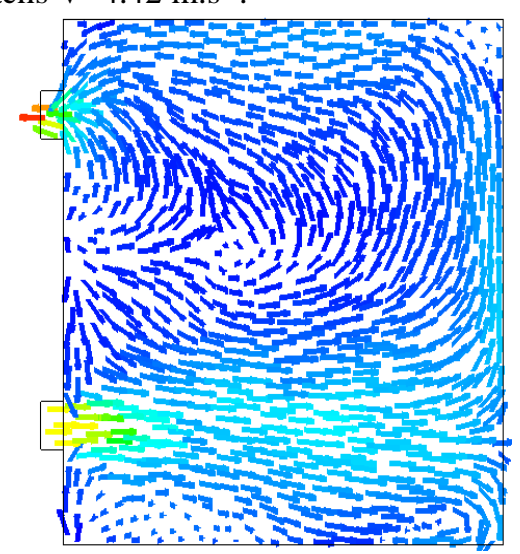

(b) BSL k- $\omega$

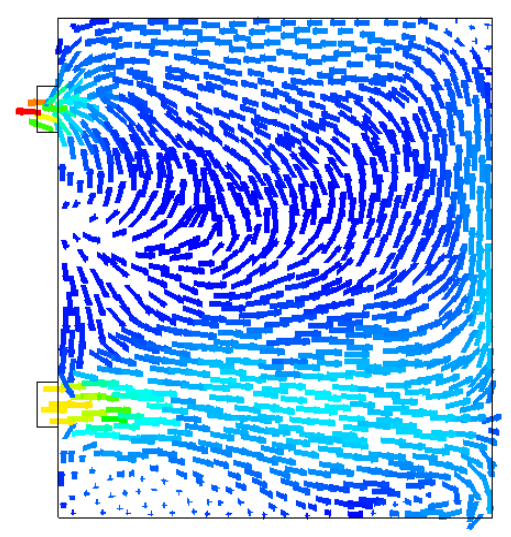

(d) Standard k- $\varepsilon$

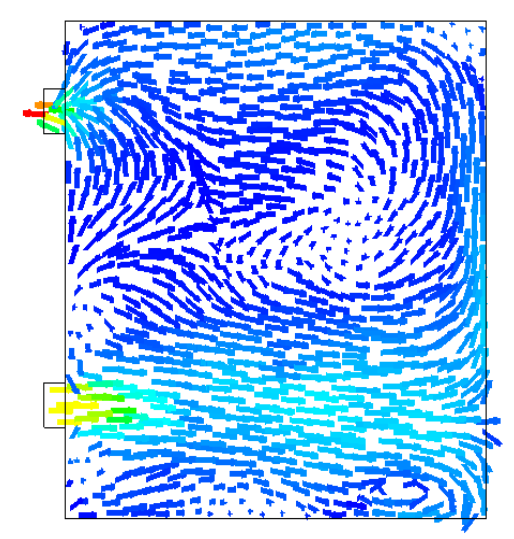

(f) Realizable k- $\varepsilon$

Fig. 5. Velocity fields. 


\subsection{Temperature}

The distribution of the air temperature at $\mathrm{t}=2 \mathrm{~s}$ and in the plane defined by $\mathrm{x}=0.06 \mathrm{~m}$ is shown in figure 6 for the considered turbulence models.

According to these results, it has been observed that the temperature at the hole inlet is equal to $\mathrm{T}=310 \mathrm{~K}$ while, it slightly decreases in the discharge area, at the hole inlet.

However, the temperature decreases above the discharge area due to the recirculation region appeared into the whole area of the box prototype.

Otherwise, the air temperature decreases gradually to reaches the minimum values at the system outlet with a value equal to $\mathrm{T}=290 \mathrm{~K}$.
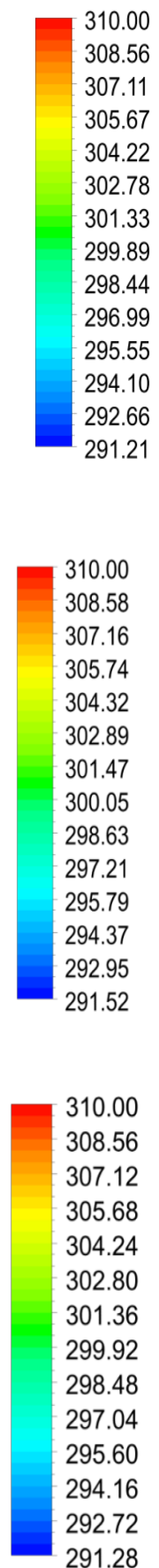

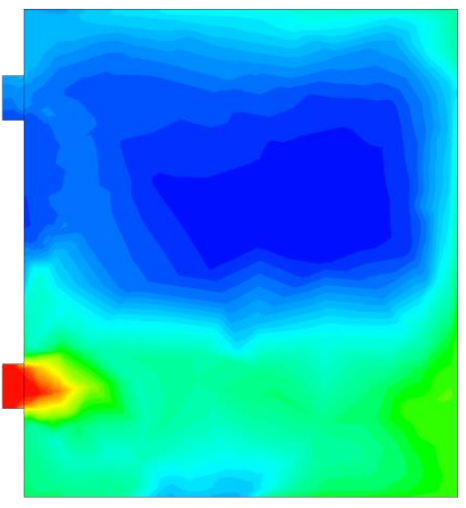

(a) Standard k- $\omega$

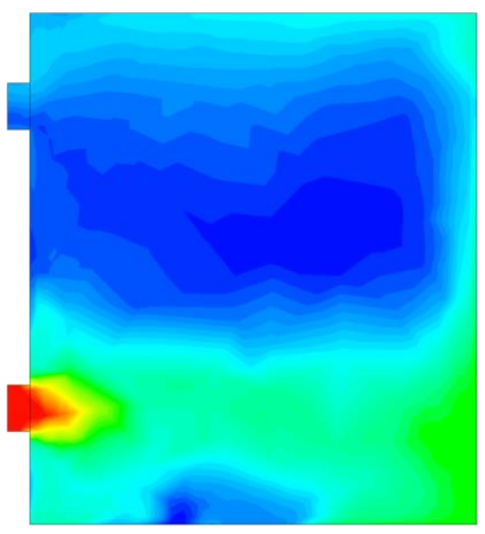

(c) SST k- $\omega$

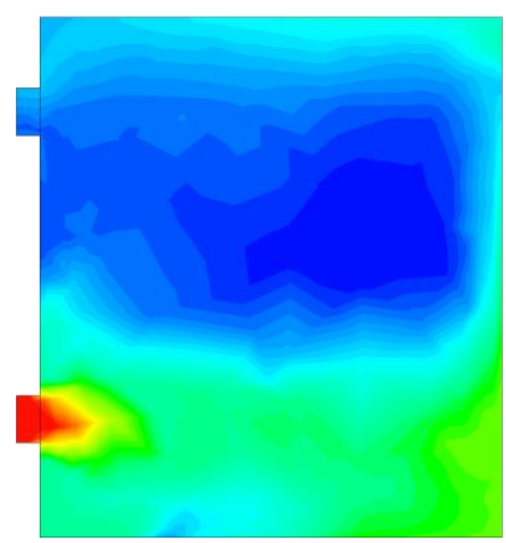

(e) RNG k- $\varepsilon$

The comparison between the founded results affirms that the choice of the turbulence model presents a straight effect on the temperature distribution.

Particularly, it has been noted that the minimum value of the temperature is obtained in the hole outlet for the BSL k- $\omega$ turbulence model and it is equal to $\mathrm{T}=290.8 \mathrm{~K}$. However, the maximum value of the temperature reaches $\mathrm{T}=291.5 \mathrm{~K}$ for the $S S T$ $k-\omega$ turbulence model.

\subsection{Total pressure}

Figure 7 shows the distribution of the total pressure in the plane defined by $\mathrm{x}=0.06 \mathrm{~m}$ for all

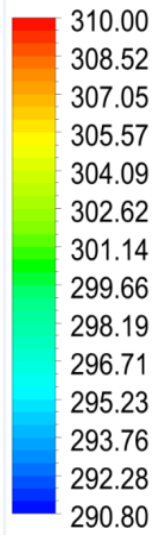

290.80

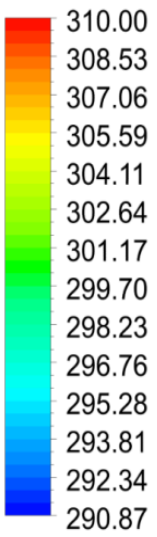

290.87

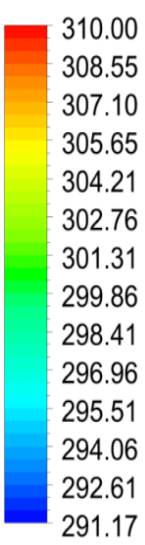

310.00

307.10

305.65

304.21

302.76

301.31

299.86

298.41

296.96

295.51

94.06

292.61

291.17

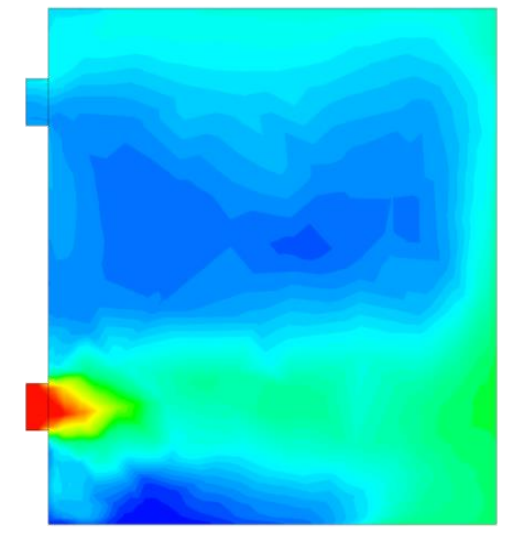

(b) BSL k- $\omega$

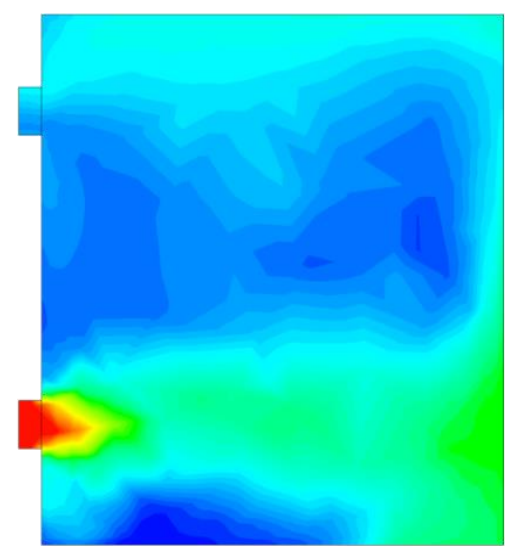

(d) Standard k- $\varepsilon$

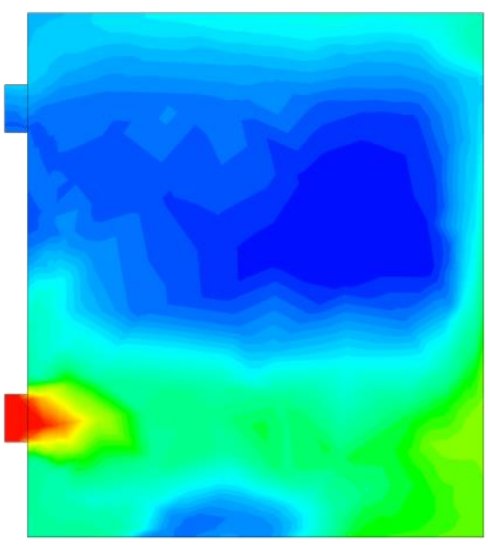

(f) Realizable k- $\varepsilon$

Fig. 6. Distribution of the temperature. 
considered turbulence models. From these results, it is clear that a compression zone is appears in the down hole of the box prototype for all cases. In

fact, the total pressure decreases delicately in the expulsion area, produced from the system inlet and attacked until the reverse wall of the box. This reality can be clarified by the recirculation zone showed at the whole area of the box prototype.

From that point onward, the total pressure increases to reaches the peak value at the opposite wall.

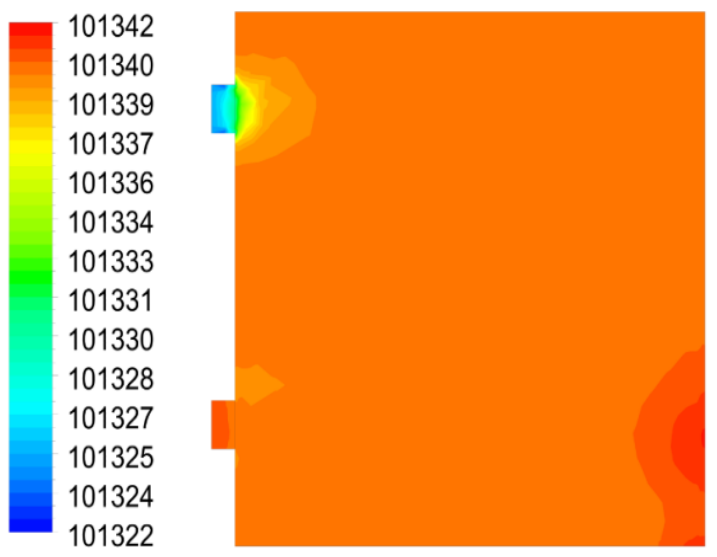

(a) Standard k- $\omega$
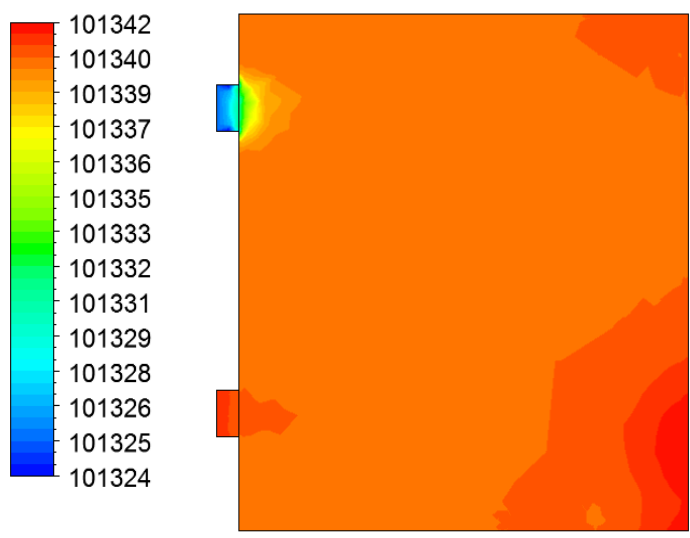

(c) SST k- $\omega$
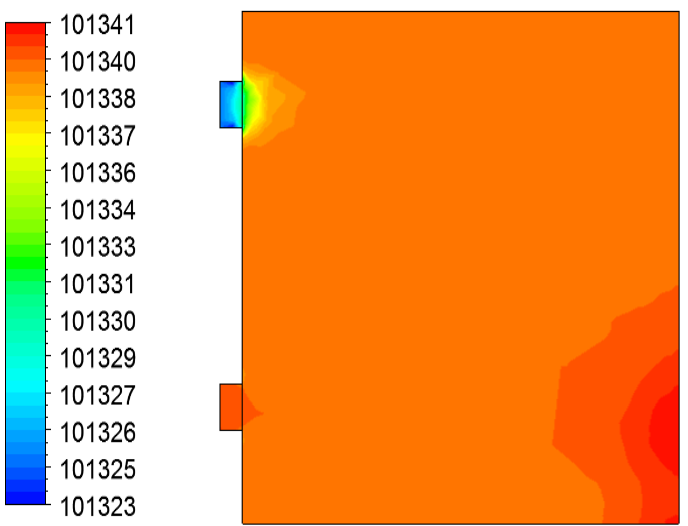

(e) RNG k- $\varepsilon$

However, a depression zone is appearing at the top hole in the system outlet for all cases.

A comparison between the different turbulence models gives that the turbulence model presents a straight effect on the distribution of the total pressure. In fact, it has been noted that the maximum value of the total pressure is founded for the standard $k-\omega$ and the SST $k-\omega$ turbulence models and presents a value equal to $\mathrm{p}=101342 \mathrm{~Pa}$.

This value decreases slightly for the other turbulence models and reaches the minimum value equal to $\mathrm{p}=101340 \mathrm{~Pa}$, for the standard $\mathrm{k}-\varepsilon$ turbulence model.
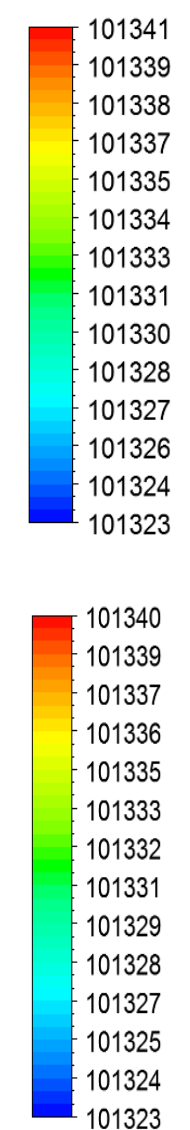

101323

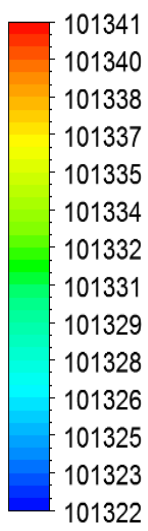

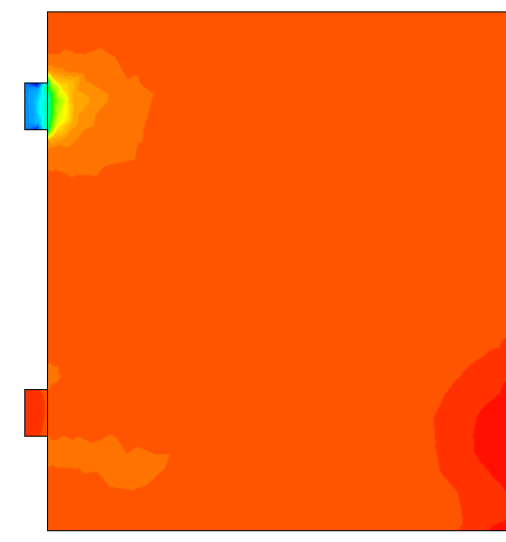

(b) BSL k- $\omega$

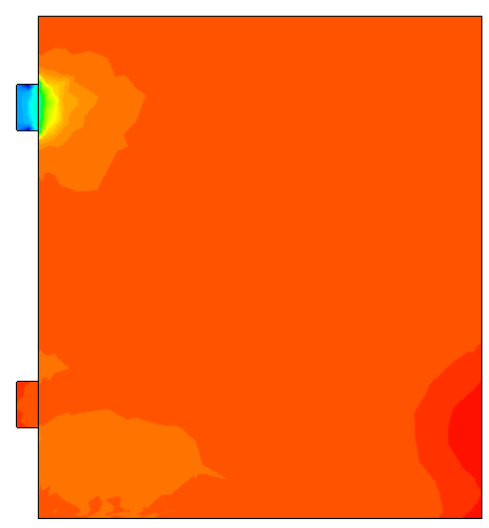

(d) Standard k- $\varepsilon$

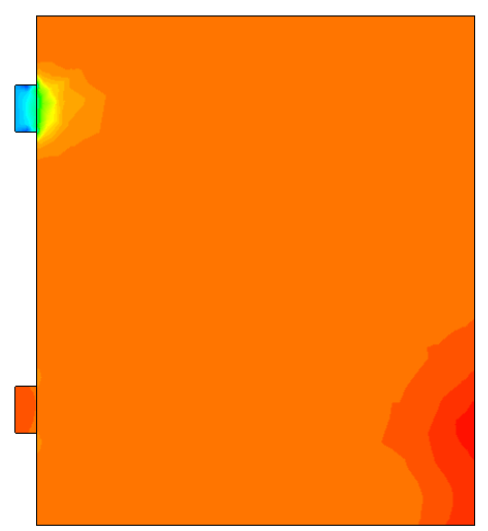

(f) Realizable k- $\varepsilon$

Fig. 7. Distribution of the total pressure. 


\subsection{Turbulent kinetic energy}

Figure 8 depicts the distribution of the turbulent kinetic energy in the plane defined by $\mathrm{x}=0.06 \mathrm{~m}$, for the considered turbulence models. From these results, it can be seen that the turbulent kinetic energy presents a small value at the system inlet. In mean time, the turbulent kinetic energy increases gradually in the expulsion area which created in the down hole of the box. Otherwise, it has been observed that the maximum turbulent kinetic energy appears at the discharge area near the reverse wall and at the top hole at the box outlet.
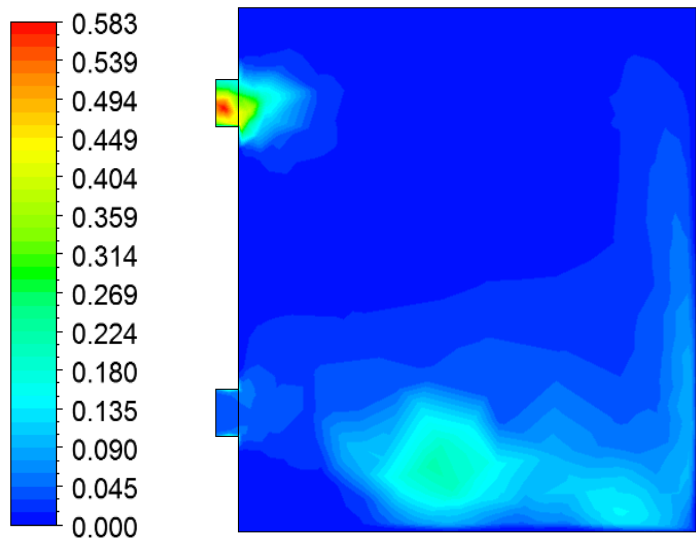

(a) Standard k- $\omega$
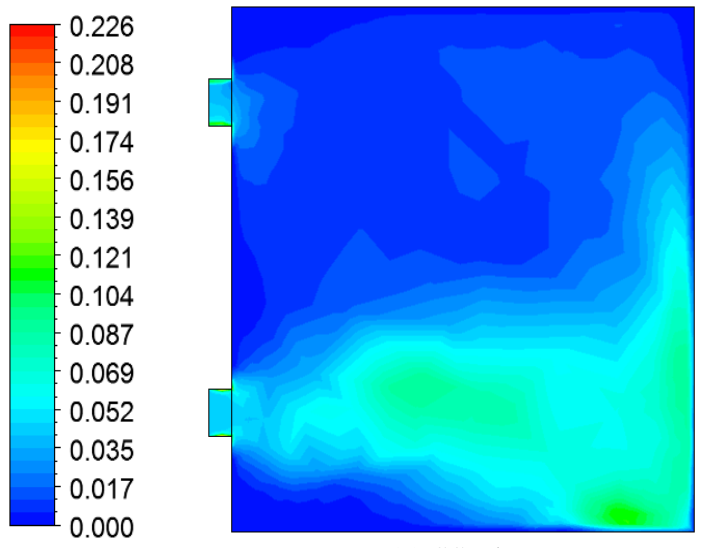

(c) SST k- $\omega$
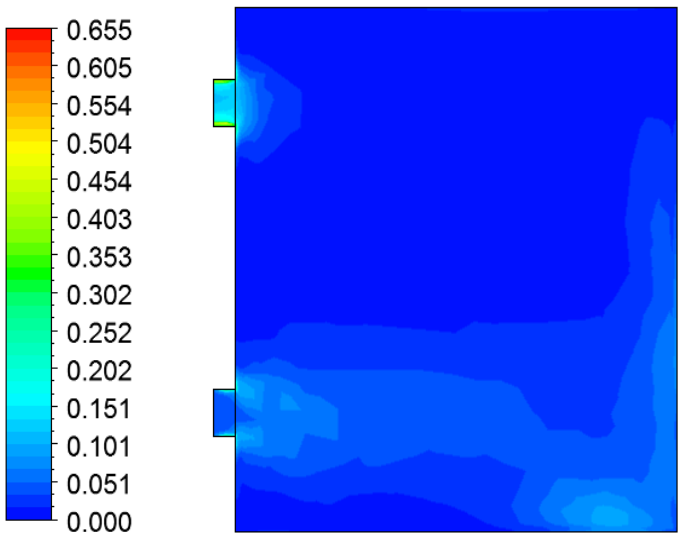

(e) RNG k- $\varepsilon$

As causes the other air proprieties, this fact is owing to the recirculation zone in the whole area of the box. Comparatively, the distribution of the turbulent kinetic energy in the four considered turbulence models affirms that the turbulence model presents a straight effect on the distribution of the turbulent kinetic energy. In fact, it has been observed that the maximum value of the turbulent kinetic energy is obtained in the hole outlet for the BSL $\mathrm{k}-\omega$ turbulence model and it reaches $\mathrm{k}=1.258$ $\mathrm{m}^{2} . \mathrm{s}^{-2}$. However, this value reaches a low value, which is about $\mathrm{k}=0.226 \mathrm{~m}^{2} \cdot \mathrm{s}^{-2}$, for the $S S T k-\omega$ turbulence model.

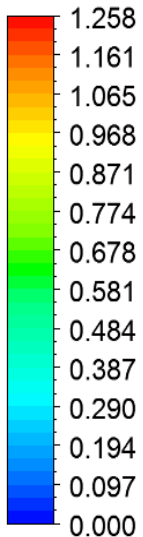

0.000
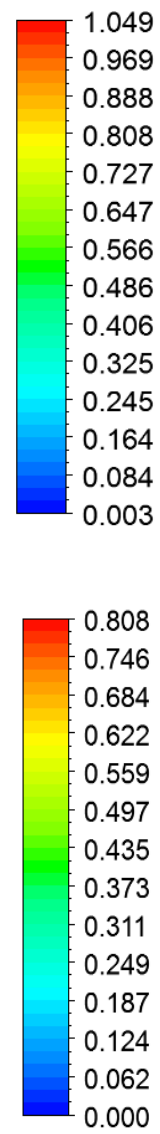

0.000

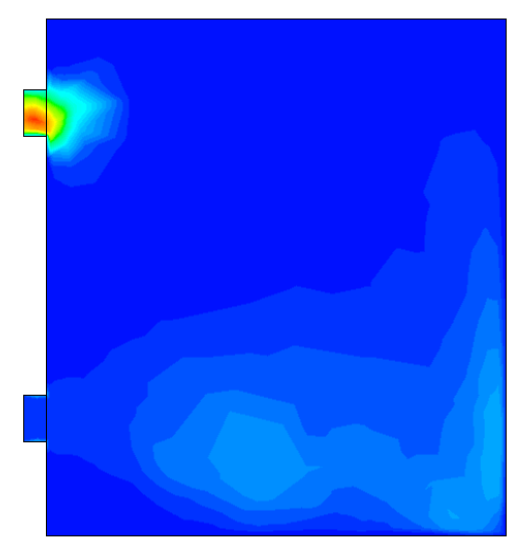

(b) BSL k- $\omega$

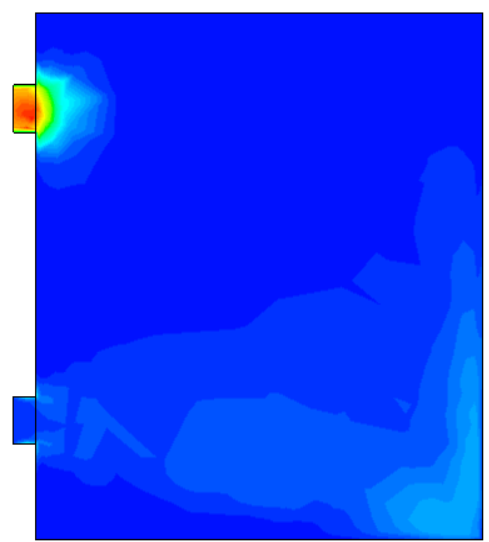

(d) Standard k- $\varepsilon$

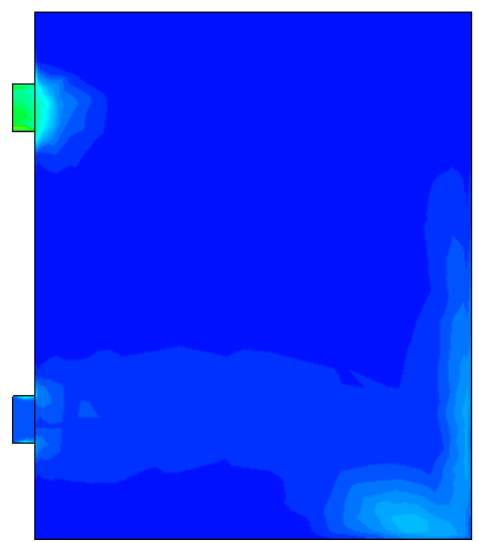

(f) Realizable k- $\varepsilon$

Fig. 8. Distribution of the turbulent kinetic energy. 


\subsection{Turbulent viscosity}

Figure 9 shows the distribution of the turbulent viscosity in the plane defined by $\mathrm{x}=0.06 \mathrm{~m}$ and for the four turbulence models. According to these results, it can be seen that the turbulent viscosity presents a small value at the box inlet for all cases. However, the turbulent viscosity roses at the expulsion area which shown in the down hole of the system. The maximum values of the turbulent viscosity appear in the discharge area near the reverse wall. Otherwise, a peak values appear at the top hole of the box prototype due to the recirculation zone of the hot air in this region.

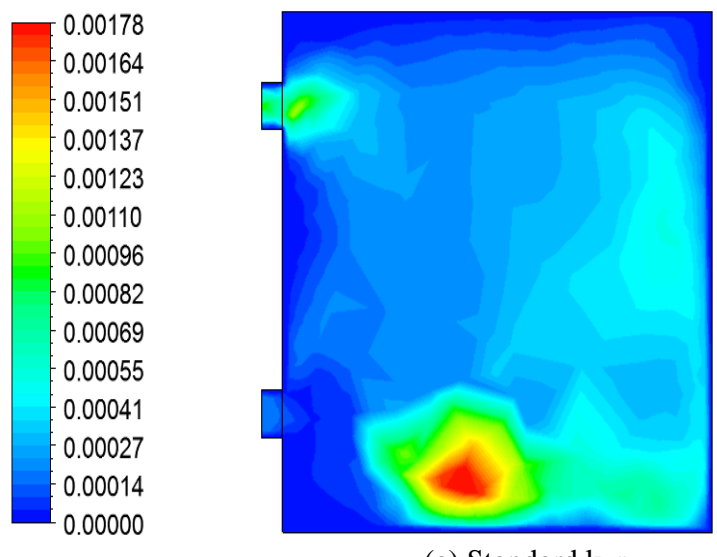

(a) Standard k- $\omega$
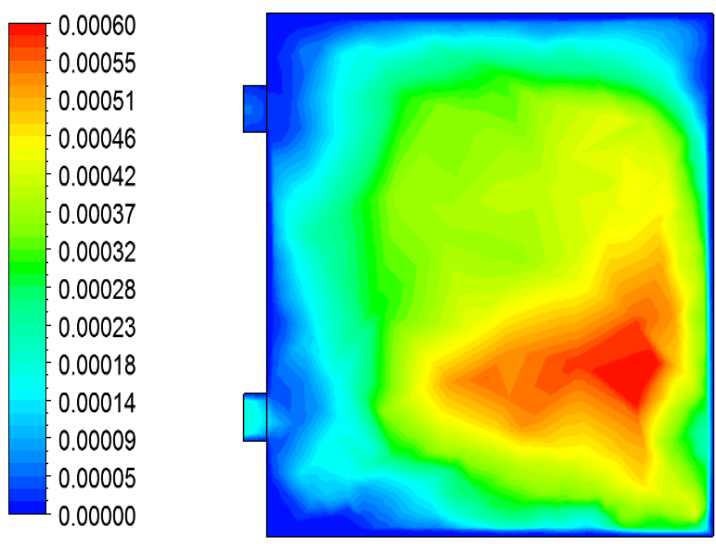

(c) SST k- $\omega$
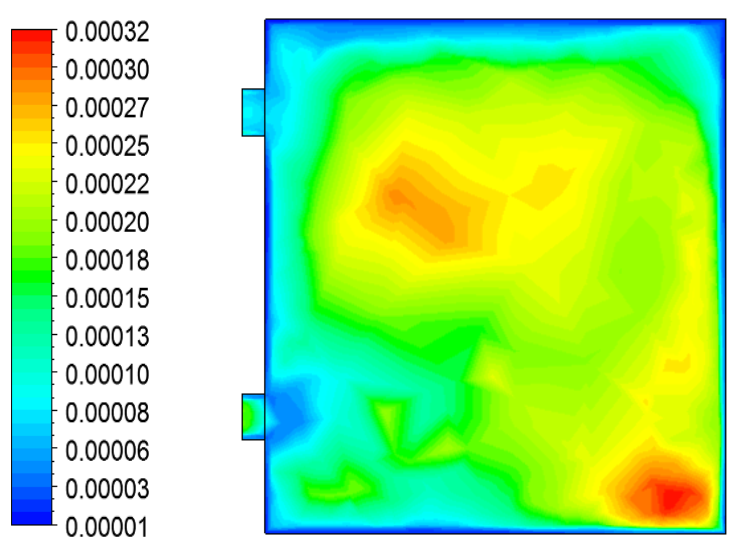

(e) RNG k- $\varepsilon$

Comparatively, it has been observed a small effect of different studied models on the distribution of the turbulent viscosity. In fact, the extension of the wake zone distinctiveness of the maximum values of the turbulent viscosity, obtained in the discharge area near the reverse wall, is more developed for the BSL k- $\omega$ turbulence model. Using this model, the maximum value of the turbulent viscosity reaches $\mu_{\mathrm{t}}=0.00192 \mathrm{~kg} \cdot \mathrm{m}^{-1} \cdot \mathrm{s}^{-1}$ in the hole outlet. However, this parameter presents a low value equal to $\mu_{\mathrm{t}}=0.00032 \mathrm{~kg} \cdot \mathrm{m}^{-1} \cdot \mathrm{s}^{-1}$ for the RNG k- $\varepsilon$ turbulence model in the discharge area. In this case, the turbulent viscosity continues to decrease immensely in the outlet hole.

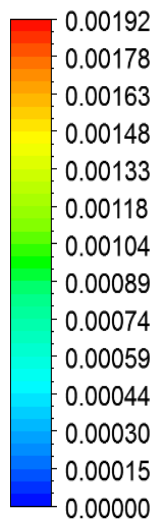

0.00124
0.00115
0.00105
0.00096
0.00086
0.00077
0.00067
0.00058
0.00048
0.00039
0.00029
0.00020
0.00010
0.00001

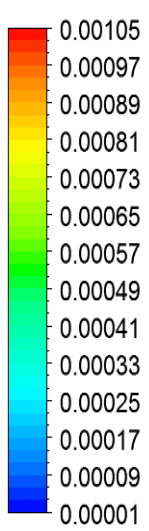

0.00001

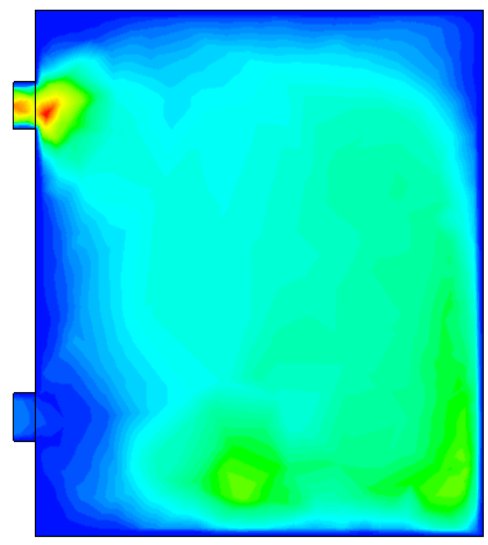

(b) BSL k- $\omega$

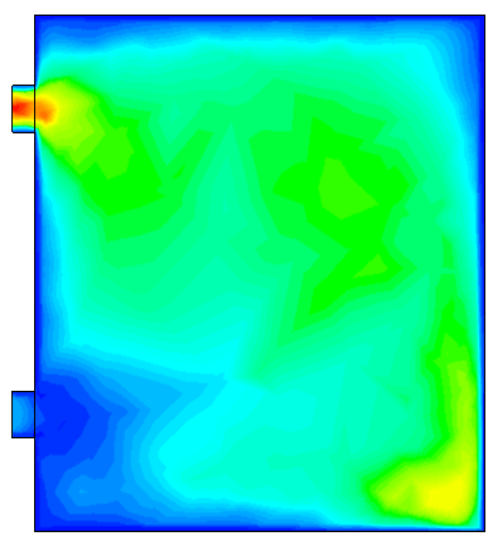

(d) Standard k- $\varepsilon$

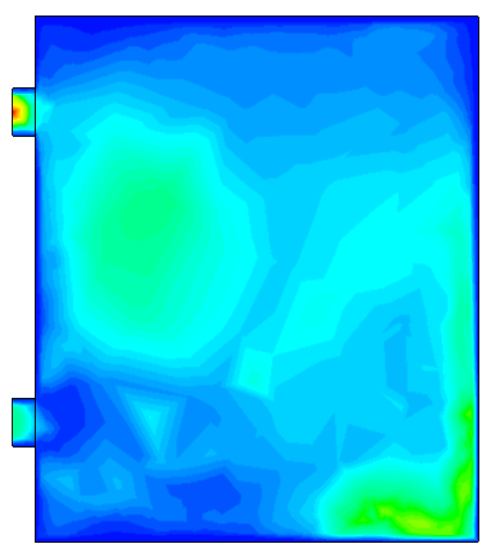

(f) Realizable k- $\varepsilon$

Fig. 9. Distribution of the turbulent viscosity. 


\section{CONCLUSION}

The present paper aims to investigate the impact of the turbulent model on the heat ventilation was studied in a box prototype equipped with a solar system. Particularly, a computational study and an experimental validation have been developed to compare the standard $k-\omega$, the SST $k-\omega$, the BSL $k$ $\omega$, the standard $k-\varepsilon$, the Realizable $k-\varepsilon$ turbulence the $R N G k-\varepsilon$ and the model. From the obtained results, it is noticed that the aerodynamic characteristics presents the same emergence nevertheless the maximum values depend on the turbulence model. Particularly, it has been noted that the value founded with the standard $k-\omega$ tubulence model is nearest to the experimental data. This study tends to show that the standard $\mathrm{k}-\omega$ turbulence model is the most efficient model to analyze the air flow in the box prototype. In the prospect, we suggest to extend this application with others geometrical arrangements.

\section{NOMENCLATURE}

\begin{tabular}{|c|c|}
\hline $\mathrm{A}_{0}$ & model constant \\
\hline $\mathrm{A}_{\mathrm{s}}$ & model constant \\
\hline $\mathrm{C}_{1}$ & model constant \\
\hline $\mathrm{C}_{1 \varepsilon}$ & $\begin{array}{l}\text { Constant of the } k-\varepsilon \text { turbulence model } \\
\text { (dimensionless) }\end{array}$ \\
\hline $\mathrm{C}_{2 \varepsilon}$ & $\begin{array}{l}\text { Constant of the } k-\varepsilon \text { turbulence model } \\
\text { (dimensionless) }\end{array}$ \\
\hline $\mathrm{C}_{\mu}$ & $\begin{array}{l}\text { Constant of the } k-\varepsilon \text { turbulence model } \\
\text { (dimensionless) }\end{array}$ \\
\hline E & Total energy $(\mathrm{J})$ \\
\hline $\mathrm{F}_{\mathrm{i}}$ & Force components on the i direction $(\mathrm{N})$ \\
\hline $\mathrm{G}_{\mathrm{k}}$ & $\begin{array}{l}\text { Generation of the turbulent kinetic energy } \\
\left(\mathrm{kg} \cdot \mathrm{m}^{-1} \cdot \mathrm{s}^{-3}\right)\end{array}$ \\
\hline $\mathrm{G}_{\mathrm{b}}$ & $\begin{array}{l}\text { Generation of turbulence kinetic energy }\left(\mathrm{kg} . \mathrm{m}^{-}\right. \\
\left.{ }^{1} \cdot \mathrm{s}^{-3}\right)\end{array}$ \\
\hline $\mathrm{G}_{\mathrm{v}}$ & Production of turbulent viscosity $\left(\mathrm{kg} \cdot \mathrm{m} . \mathrm{s}^{-2}\right)$ \\
\hline $\mathrm{G}_{\omega}$ & $\begin{array}{l}\text { Generation of the dissipation rate of the } \\
\text { turbulent kinetic energy }\left(\mathrm{kg} \cdot \mathrm{m}^{-1} \cdot \mathrm{s}^{-3}\right)\end{array}$ \\
\hline $\mathrm{H}$ & Height (m) \\
\hline $\mathrm{h}$ & Thermal enthalpy $\left(\mathrm{J}^{\mathrm{kg}} \mathrm{kg}^{-1}\right)$ \\
\hline $\mathrm{k}$ & Turbulent kinetic energy $\left(\mathrm{m}^{2} \cdot \mathrm{s}^{-2}\right)$ \\
\hline 1 & Length (m) \\
\hline $\mathrm{p}$ & Pressure $(\mathrm{Pa})$ \\
\hline$P_{r}$ & Prandt number \\
\hline $\mathrm{QH}_{\mathrm{H}}$ & Heat source or sink per unit volume $\left(\mathrm{kg} \cdot \mathrm{m}^{-1} \cdot \mathrm{s}^{-3}\right)$ \\
\hline$q_{i}$ & Diffusive heat flux $(J)$ \\
\hline $\operatorname{Re}$ & Reynolds number (dimensionless) \\
\hline $\mathrm{R}_{\mathrm{k}}$ & $\begin{array}{l}\text { Constant of the k- } \omega \text { turbulence model } \\
\text { (dimensionless) }\end{array}$ \\
\hline $\mathrm{R}_{\omega}$ & $\begin{array}{l}\text { Constant of the k- } \omega \text { turbulence model } \\
\text { (dimensionless) }\end{array}$ \\
\hline $\mathrm{S}$ & Scalar measure of the deformation tensor \\
\hline $\mathrm{S}_{\mathrm{i}}$ & Mass-distributed $\left(\mathrm{kg} \cdot \mathrm{m}^{-2} \cdot \mathrm{s}^{-2}\right)$ \\
\hline$S_{i j}$ & Mean rate-of-strain tensor $\left(\mathrm{s}^{-1}\right)$ \\
\hline $\mathrm{S}_{\omega}$ & $\begin{array}{l}\text { Source terms of the specific dissipation rate of } \\
\text { the turbulent kinetic energy }\left(\mathrm{kg} \cdot \mathrm{m}^{-1} \cdot \mathrm{s}^{-3}\right)\end{array}$ \\
\hline $\mathrm{S}_{\mathrm{k}}$ & $\begin{array}{l}\text { Source terms of the turbulent kinetic energy } \\
\left(\mathrm{kg} \cdot \mathrm{m}^{-1} \cdot \mathrm{s}^{-3}\right)\end{array}$ \\
\hline$S_{\varepsilon}$ & $\begin{array}{l}\text { Source terms of the dissipation rate of the } \\
\text { turbulent kinetic energy }\left(\mathrm{kg} \cdot \mathrm{m}^{-1} \cdot \mathrm{s}^{-3}\right)\end{array}$ \\
\hline $\mathrm{T}$ & Temperature $(\mathrm{K})$ \\
\hline
\end{tabular}

Time (s)

u Velocity components $\left(\mathrm{m} \cdot \mathrm{s}^{-1}\right)$

$\mathrm{u}_{\mathrm{i}}{ }^{\prime} \quad$ Fluctuating velocity components $\left(\mathrm{m} \cdot \mathrm{s}^{-1}\right)$

V Magnitude velocity $\left(\mathrm{m} . \mathrm{s}^{-1}\right)$

$\mathrm{xi}_{\text {i }} \quad$ Cartesian coordinate $(\mathrm{m})$

$\mathrm{x} \quad$ Cartesian coordinate $(\mathrm{m})$

y Cartesian coordinate $(\mathrm{m})$

$\mathrm{Y}_{\mathrm{M}} \quad$ Fluctuating dilatation in compressible turbulence $\left(\mathrm{kg} \cdot \mathrm{m}^{-1} \cdot \mathrm{s}^{-3}\right)$

$\mathrm{Y}_{\mathrm{k}} \quad$ Turbulence dissipation of $\mathrm{k}$

$\mathrm{Y}_{\omega} \quad$ Turbulence dissipation of $\omega$

$\mathrm{z} \quad$ Cartesian coordinate $(\mathrm{m})$

U Free-stream velocity $(\mathrm{m} / \mathrm{s})$

$\eta_{0} \quad$ Constant of the $k-\varepsilon$ turbulence model (dimensionless)

$\alpha_{0} \quad$ Constant of the $k-\omega$ turbulence model (dimensionless)

$\alpha_{\infty} \quad$ Constant of the $k$ - $\omega$ turbulence model (dimensionless)

$\alpha_{\infty}^{*} \quad$ Constant of the $k$ - $\omega$ turbulence model (dimensionless)

$\delta_{\mathrm{ij}} \quad$ Kronecker delta function (dimensionless)

$\beta \quad$ Constant of the $k-\varepsilon$ turbulence model (dimensionless)

$\varepsilon \quad$ Dissipation rate of the turbulent kinetic energy $\left(\mathrm{m}^{2} \cdot \mathrm{s}^{-3}\right)$

$\mu \quad$ Dynamic viscosity (Pa.s)

$\mu_{\mathrm{t}} \quad$ Turbulent viscosity (Pa.s)

$\mu_{\text {eff }} \quad$ Effective viscosity (Pa.s)

$\omega \quad$ Specific dissipation rate $\left(\mathrm{s}^{-1}\right)$

$\rho \quad$ Density $\left(\mathrm{kg} \cdot \mathrm{m}^{-3}\right)$

$\beta_{\mathrm{i}} \quad$ Constant of the $\mathrm{k}-\omega$ turbulence model (dimensionless)

$\sigma_{\mathrm{k}} \quad$ Constant of the k- $\varepsilon$ turbulence model (dimensionless)

$\sigma_{\varepsilon} \quad$ Constant of the k- $\varepsilon$ turbulence model (dimensionless)

$\sigma_{\mathrm{k}} \quad$ Turbulent Prandtl number for $\mathrm{k}$ (dimensionless)

$\sigma_{\omega} \quad$ Turbulent Prandtl number for $\omega$ (dimensionless)

$\tau_{\mathrm{ij}} \quad$ Viscous shear stress tensor $(\mathrm{Pa})$

$\left(\tau_{\mathrm{ij}}\right)_{\text {eff }} \quad$ Deviatoric stress tensor $(\mathrm{Pa})$

$\Phi \quad$ Equivalence ratio (dimensionless)

$\Gamma_{\mathrm{k}} \quad$ Effective diffusivity of $\mathrm{k}$

$\Gamma_{\omega} \quad$ Effective diffusivity of $\omega$

$\Omega \quad$ Swirl number (dimensionless)

$\Omega_{\mathrm{ij}} \quad$ Rate of rotation tensor $\left(\mathrm{s}^{-1}\right)$

\section{ACKNOWLEDGMENTS}

The authors would like to thank Prof. Zied Driss from the Engineering School of Sfax for her help in English proofreading.

\section{REFERENCES}

1. Bakri B, Driss S, Ketata A, Driss Z, Benguesmia H, Hamrit F. Study of the Heat Ventilation in a Box Prototype With the k- $\omega$ Turbulence Model. Transylvanian Review journal. 2018; XXXVI (30):7989-8000.

https://transylvanianreviewjournal.org/index.php/TR/article/ view/3054

2. Bakri B, Eleuch O, Ketata A, Driss S, Driss Z, Benguesmia H. Study of the turbulent flow in a newly solar air heater test bench with natural and forced convection modes. Energy. 2018;161:10281041. https://doi.org/10.1016/j.energy.2018.07.187 
3. Bakri B, Ketata A, Driss S, Benguesmia H, Driss Z, Hamrit F. Unsteady investigation of the heat ventilation in a box prototype. International Journal of Thermal Sciences. 2019;135:285-297. https://doi.org/10.1016/j.ijthermalsci.2018.09.023

4. Driss S, Driss Z, Kammoun I. Computational study and experimental validation of the heat ventilation in a living room with a solar patio system. Energy and building. 2016;119:28-40.

https://doi.org/10.1016/j.enbuild.2016.03.016

5. Ayadi A, Driss Z, Bouabidi A, Nasraoui H, Bsisa M, Abid MS. A computational and an experimental study on the effect of the chimney height on the thermal characteristics of a solar chimney power plant. Journal of Process Mechanical Engineering. 2017;231:1-14. https://doi.org/10.1177/0954408917719776

6. Driss S, Driss Z, Kammoun I. Numerical simulation and wind tunnel experiments on wind-induced natural ventilation in isolated building with patio. Energy. 2015;90:917-925. https://doi.org/10.1016/j.energy.2015.07.128

7. Teodosiu C, Kuznik F, Teodosiu R. CFD modeling of buoyancy driven cavities with internal heat sourceApplication to heated rooms. Energy and Buildings. 2014;68:403-411. https://doi.org/10.1016/j.enbuild.2013.09.041

8. Du X, Bokel R, Dobbelsteen AVD. Building microclimate and summer thermal comfort in freerunning buildings with diverse spaces: a Chinese vernacular house case. Building and Environment. 2014;822:215-227. https://doi.org/10.1016/j.buildenv.2014.08.022

9. Homod RZ. Assessment regarding energy saving and decoupling for different AHU (air handling unit) and control strategies in the hot-humid climatic region of Iraq. Energy. 2014;74:762-774. https://doi.org/10.1016/j.energy.2014.07.047

10. Terrados FJ, Moreno D. "Patio" and "Botijo": Energetic strategies' architectural integration in"Patio 2.12" prototype. Energy and Buildings. 2014;83:7088. https://doi.org/10.1016/j.enbuild.2014.03.081

11. Yasa E. Microclimatic comfort measurements evaluation of building physics: The effect of building form and building settled area, on pedestrian level comfort around buildings. Journal of Building Physics. 2016;40:472-500. https://doi.org/10.1177/1744259115621979

12. Premrov M, Leskovar VZ, Mihalic K. Influence of the building shape on the energy performance of timber-glass buildings in different climatic conditions. Energy. 2016;108:201-211. https://doi.org/10.1016/j.energy.2015.05.027

13. Johnston D. Dominic Miles-Shenton, David Farmer. Quantifying the domestic building fabric 'performance gap'. Building Services Engineering Research and Technology. 2015;36:614-627. https://doi.org/10.1177/0143624415570344

14. Chan ALS. Investigation on the appropriate floor level of residential building for installing balcony, from a view point of energy and environmental performance. A case study in subtropical Hong Kong. Energy. 2015;85:620-634. https://doi.org/10.1016/j.energy.2015.04.001

15. Ibrahim M, Wurtz E, Biwole $\mathrm{PH}$, Achard P. Transferring the south solar energy to the north facade through embedded water pipes. Energy. 2014;78:834-845.

https://doi.org/10.1016/j.energy.2014.10.078
16. Nam Y, Chae HB. Numerical simulation for the optimum design of ground source heat pump system using building foundation as horizontal heat exchanger. Energy. 2014;73:933-942. https://doi.org/10.1016/j.energy.2014.06.108

17. Alam MR, Zain MFM, Kaish ABMA, Jamil M. Underground soil and thermal conductivity materials based heat reduction for energy-efficient building in tropical environment. Indoor and Built Environment. 2013;24:185-200. https://doi.org/10.1177/1420326X13507591

18. Rode C. Global building physics. Journal of Building Physics. 2012;36:337-352. https://doi.org/10.1177/1744259112462107

19. Han HJ, Jeon YI, Lim SH, Kim WW, Chen K. New developments in illumination, heating and cooling technologies for energy-efficient buildings. Energy. 2010;35:2647-2653. https://doi.org/10.1016/j.energy.2009.05.020

20. Watson KJ, Evans J, Karvonen A, Whitley T. Reconceiving building design quality: A review of building users in their social context. Indoor and Built Environment. 2014;25:509-523. https://doi.org/10.1177/1420326X14557550

21. Sailor DJ, Elley TB, Gibson M. Exploring the building energy impacts of green roof design decisions - a modeling study of buildings in four distinct climates. Journal of Building Physics. 2011;35:372-391. https://doi.org/10.1177/1744259111420076

22. Bakri B, Driss S, Ketata A, Benguesmia H, Hamrit F, Driss Z. Study of the meshing effect on the turbulent flow in a building system with a $\mathrm{k}-\omega$ turbulence model. International Conference on Mechanics and Energy (ICME'2016), December 22-24 2016, Hammamet, Tunisia.

23. Driss Z, Mlayeh O, Driss D, Maaloul M, Abid M.S. Numerical simulation and experimental validation of the turbulent flow around a small incurved Savonius wind rotor. Energy. 2014;74:506-517. https://doi.org/10.1016/j.energy.2014.07.016

24. Driss Z, Bouzgarrou G, Chtourou W, Kchaou H, Abid MS. Computational studies of the pitched blade turbines design effect on the stirred tank flow characteristics. European Journal of Mechanics B/Fluids. 2010;29:236-245. https://doi.org/10.1016/j.euromechflu.2010.01.006

25. Driss Z, Mlayah O, Driss S, Maaloul M, Abid MS. Study of the incidence angle effect on the aerodynamic structure characteristics of an incurved Savonius wind rotor placed in a wind tunnel. Energy. 2016;113:894-908. https://doi.org/10.1016/j.energy.2016.07.112

26. Driss Z, Mlayah O, Driss S, Driss D, Maaloul M, Abid MS. Study of the bucket design effect on the turbulent flow around unconventional Savonius wind rotors. Energy. 2015;89:708-729. https://doi.org/10.1016/j.energy.2015.06.023

Received 2020-04-03

Accepted 2020-07-13

Available online 2020-07-15

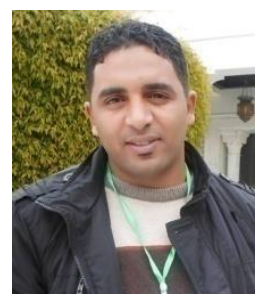

Hani BENGUESMIA was born in Bou-saada, M'sila, Algeria. He received his DEUA diploma in 2006, his Engineering Diploma in 2009, his magister Degree in 2012, 
his $\mathrm{PhD}$ in 2018 in Electrical Engineering from Mohamed kheider University, Biskra, and his HDR in 2020 in Electrical Engineering from Mohamed Boudiaf University, M'sila, Algeria. He has been working for more than five years with the Department of Electrical Engineering, University of M'sila, as a Professor. His main research interests include high voltage, outdoor insulation, CFD simulation, numerical modeling and simulation. $\mathrm{He}$ is the author or co-author of several technical papers published in different journals and reviews.

E-mail address: hanibenguesmia16@gmail.com \& hani.benguesmia@univ-msila.dz

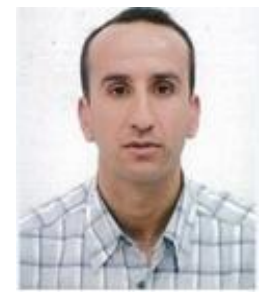

Badis BAKRI was born in M'sila, Algeria. He received from Badji Mokhtar University of Annaba Algeria his Mechanical Licence diploma in 1995 and his Master degree from Mohamed Boudiaf University of M'sila Algeria in Mechanical Engineering in 2011, and doctorate degree in mechanical engineering from the National School of Engineers of Sfax (ENIS) in 2018. He is interested in the field of numerical analysis of mechanical systems and energy applications. Also, his research has been focused on, renewable energy, fluid flow and numerical computation. ). He is author of different articles published in different journals and reviews.

E-mail address:

badisbakri@yahoo.fr \& badis.bakri@univ-msila.dz

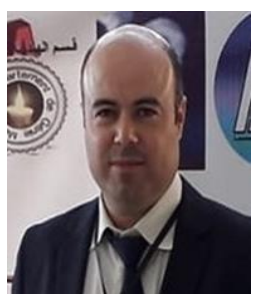

Prof. Zied DRISS is Full Professor in the Department of Mechanical Engineering at National School of Engineers of Sfax (ENIS). He received his Engineering Diploma in 2001, his Master Degree in 2003, his $\mathrm{PhD}$ in 2008 and his HDR in 2013 in Mechanical Engineering from ENIS at University of Sfax, Tunisia. He is interested on the development of numerical and experimental techniques for solving problems in mechanical engineering and energy applications. Also, his research has been focused on the interaction between Computational Fluid Dynamics (CFD) and Computational Structure Dynamics (CSD) codes. As a result of his research, he is principal or co-principal investigator on more than 160 papers in peer-reviewed journals, more than 350 communications to international conferences, 20 books and 70 books chapters. Also, he is the main inventors of 10 patents.

Currently, Prof. Driss is a Team Leader in the Laboratory of Electromechanical Systems (LASEM), an Editorial Board Member and reviewer for different international journals, an Editor for different books, a General Chair of two bi-annual international conferences and an active member in different national and international associations.

E-mail address:

zied.driss@enis.tn \& zied_driss@yahoo.fr

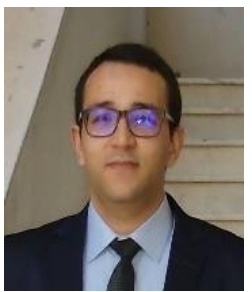

Ahmed KeTATA is a postdoctoral researcher in the Laboratory of Electro-Mechanical Systems (LASEM) located in Tunisia. He was born in Sfax, Tunisia. In June 2015, he graduated from the University of Carthage, Tunisia with an Engineering degree in Mechanical Engineering. $\mathrm{He}$ received his Ph.D. diploma in Mechanical Engineering in 2018 from the National Engineering School of Sfax. He works in the field of fluid mechanics and its industrial applications. Particularly, His Ph.D. thesis project has been focused on turbo charging systems of Internal Combustion Engines (ICE). Further, he has software and web development skills using different programming languages like $\mathrm{C}++$, Python and PHP. He is interested in CFD, FSI, thermodynamics and acoustic analyses of rotating machinery and fluid dynamic systems.

E-mail address:

ketata.ahmed.enib@gmail.com \& ahmed.ketata@enis.tn

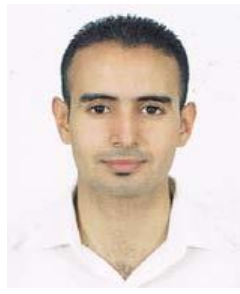

Slah DRISS born in Sfax Tunisia, at $31^{\text {th }}$ August 1985 . He received his architecture diploma in 2010, from National School of Architecture of Tunis, Tunisia. He is interested in the field of analysis of fluid mechanical problems and energy applications. Also, his research has been focused on the interaction between Computational Fluid Dynamics (CFD). He is author of different articles published in different journals and reviews.

E-mail address:

slah.driss@gmail.com 